\title{
The Impact Of Culture On The Purchase Of Life Insurance In Latin America And The Caribbean
}

James R. Eck, (E-mail: james.eck@washburn.edu), Washburn University

Dmitri Nizovtsev, (E-mail: dmitri.nizovtsev@washburn.edu), Washburn University

\begin{abstract}
This study attempts to determine the major reasons for the lack of success in marketing life insurance in Latin America and the Caribbean. Our results point at the importance of cultural variables of which the most significant is the percentage of the population that professes to be Catholic. We attribute this to a strong correlation between religious beliefs and risk preferences. The other major factor is the population's attitude toward financial instruments in general. Both results are robust to the model specification. The findings should be of interest to insurance companies attempting to market life insurance throughout the world.
\end{abstract}

\section{INTRODUCTION}

$\mathscr{I}$

$\mathrm{t}$ is widely acknowledged in economics and marketing literature that broadly defined "culture" plays an important role in consumers' preferences. Therefore, one of the first things a firm must do prior to entering a foreign market is to understand the culture of the host country. Some of the factors characterizing a country's culture are customs and traditions, political philosophy, demographics and social structure of the society, the dominant religion, language, and education (Hill, 2005). Several of these factors are quantifiable while other are qualitative and cannot be as easily analyzed.

Life insurance products are especially good candidates for studying the relationship between culture and preferences due to the straightforward link between the demand for them and the degree of risk aversion among the country's population, which is clearly one of the aspects of national culture. ${ }^{1}$

The rate at which life insurance is purchased in various countries varies greatly. The variable commonly used to measure purchases of life insurance in a particular country is life insurance penetration rate (LIPR), represented by the percentage share of the Gross Domestic Product (GDP) spent on life insurance premiums. The penetration rate ranges from $0.01 \%$ in Saudi Arabia and Ukraine, to $15.19 \%$ in South Africa. The possible reasons for such a striking difference across countries have been of interest to researchers for a long time.

The earliest studies of LIPR determinants focused on per capita income level as the most important factor. However, economic factors alone fail to explain the variation in LIPR. Later and more comprehensive studies consistently show that the relationship between income and LIPR is positive but weak, and that other factors of noneconomic nature may matter as well (Beenstock et al., 1986; Browne and Kim, 1993; Outreville, 1996; Beck and Webb, 2003).

\footnotetext{
${ }^{1}$ The link between a country's culture and people's attitude to risk has been previously discussed by several researchers. For example, Douglas and Wildavsky (1982) conclude that “... acceptable risk is a matter of judgment and nowadays judgments differ. Between private, subjective perception and public, physical science there lies culture, a middle area of shared beliefs and values. The present division of the subject that ignores culture is arbitrary and self-defeating" (p.194).
} 
In our paper, we test a number of factors as determinants of life insurance consumption, ${ }^{2}$ but we are first and foremost interested in cultural issues, especially in that of fatalism. The correlation between fatalism and the attitude toward life insurance has been pointed out by several researchers. For instance, Burnett and Palmer (1984) used data from a consumer panel in one of the U.S. cities to find that people who don't believe in fate buy significantly greater amount of insurance. Faulkner (2002) attributes low life insurance penetration in Hong Kong to oriental fatalism.

How to measure fatalism at the macro level is another question. In the absence of a better proxy, we use the prevailing system of religious beliefs in a country as the proxy for the population's attitude to fate issues and therefore for the degree of risk aversion. ${ }^{3}$ In fact, previously Browne and Kim (1993) and Beck and Webb (2003) used this approach and found a strong negative relationship between the percentage of Islamic believers within the population and LIPR. Their studies, however, single out Islam from the set of all religions. This is somewhat justified as Islam is probably the most fatalistic of all the world religions but leaves many questions wide open. For one, it is worth noting that there are sizeable geographical regions where the Muslim religion is not well represented. One example of such a region is Latin America and the Western hemisphere in general, where the share of Islamic believers in the population is extremely small. This was one of the reasons this study is focused on the Western hemisphere.

Another reason to be interested in Latin America and the Caribbean is the fact that the average LIPR in this region is only 0.72 percent (Sigma, 2002). This is substantially below the world average of 4.68 percent. Understanding the reasons for such a striking difference is very important, especially since Latin America represents a large market with a potential for growth in life insurance consumption. Hence our study focuses on the analysis of the factors affecting the countries' consumption of life insurance using cross-sectional data on eighteen countries located in the Western Hemisphere.

Among the religious denominations represented in the Western hemisphere, we found Catholic religion to be the most consistent with fatalism. While the Catholic Church does not adhere to fatalism directly, it does believe in the promise of salvation in the next world rather than this world (Hill, 2005). Many Catholics believe that God will not give them more than they can accept and therefore they accept what happens at the will of God. This is especially important for our sample of countries since, as Carreyrou et al. (2003) point out, "Catholics in the developing world tend to be more conservative doctrinally, place more emphasis on mysticism... use the church as a social and political force to improve their lot." In our paper, we use the percentage of a country's population that considers themselves Catholic as a measure of the prevalence of Catholic religion and therefore the degree to which fatalistic beliefs are shared by the country's population.

We are also interested in the overall population's familiarity with and attitude to financial instruments that allow to transfer wealth to future generations. We use the share of savings in a country's GDP as an indicator of such attitude, thus perceiving it as a cultural, not economic variable. As will be shown later in the paper, both cultural variables turned out to be highly significant.

The rest of the paper is organized as follows. The next section presents a theoretical model of life insurance purchases and discusses factors that may be of interest in an empirical study. The model, data set, and empirical methodology are discussed in Section III. Section IV summarizes the results and discusses their implications. Finally, Section V concludes and outlines some directions for further research.

\section{THEORETICAL MOTIVATION}

All the existing theoretical models of life insurance treat it as the tool that allows the household to reduce uncertainty in its income stream caused by the possibility of premature death of the primary income earner (Yaari, 1965; Fischer, 1973; Pissarides, 1980; Lewis, 1989). The focus of the last paper is on the maximization of the

\footnotetext{
${ }^{2}$ Preserving consistency with prior studies, we also incorporate in our analysis a number of commonly recognized factors affecting LIPR, including life expectancy, education attainment, per capita income, inequality of income distribution, and others. Those factors are discussed in more detail in Section III.

${ }^{3}$ Apparently, religious beliefs are not the only factor that affects risk aversion. Still, we used it due to the lack of a better macro level indicator of attitude to risk. Our results below indicate that such an approach was at least somewhat justified.
} 
beneficiaries' expected utility while the others model the problem as the decision of the primary income earner maximizing the weighted sum of his utility from consumption and that from bequests. The models yield qualitatively similar results that do not depend on model specification.

We use the discrete-time model of Fischer (1973) as the starting point in our analysis. According to Fischer's specification, the demand for insurance is derived from an individual's expected utility function,

$$
E\left[\sum_{t=1}^{T}\left(\tilde{\pi}_{t}^{a} \frac{C_{t}^{1-\beta}}{(1-\beta)} \frac{1}{(1+\rho)^{t-1}}+\tilde{\pi}_{t+1}^{d} b_{t+1} \frac{G_{t+1}^{1-\beta}}{(1-\beta)}\right)\right],
$$

where $T$ is the maximum number of periods an individual can live, $\tilde{\pi}_{t}^{a}$ is the probability he is alive in any period $t$, $\tilde{\pi}_{t}^{d}$ is the probability he dies at the beginning of period $t$. In any period the individual is alive he obtains utility from consumption, $C_{t}$, and if he dies, then utility is attached to the bequests he leaves, $G_{t}$. Parameter $\beta$ determines the specific form of the utility function, and $\rho$ is the discounting factor. Parameter $b_{t}$ denotes the weight placed on bequests in period $t{ }^{4}$ Fischer follows Yaari (1965) in pointing out that in order for a consumer's objective function to be maximized, the marginal utility of consumption has to equal the marginal utility of bequests at every moment. Thus the provided utility specification allows us to discuss the expected effect of various economic and demographic variables on the decision to purchase life insurance. Greater household income decreases the marginal utility of consumption, thus it is reasonable to expect the demand for life insurance to increase with an increase in household income. Higher inflation rate decreases the marginal utility of bequests and thus negatively affects the demand for insurance. A larger number of dependents per working member of a household results in a larger weight attached to bequests, $b_{t}$. This, in turn, increases the marginal utility of bequests and should therefore result in higher demand for insurance. Longer expected life span increases $\tilde{\pi}_{t}^{a}$ and reduces $\tilde{\pi}_{t}^{d}$, thus shifting the optimal choice towards more consumption and less insurance purchased..$^{5}$

Parameter $\beta$ is crucial in the above utility formulation since it in fact determines the specific form of the utility function and therefore the characteristics of the derived demand. The value of this parameter depends on a variety of cultural and demographic factors, some of which are discussed in the Introduction. One such factor is the consumers' attitude to risk. Stronger risk aversion on the buyers' part corresponds to larger values of $\beta$ and therefore stronger demand for life insurance products.

Finally, a higher education level of the population increases the likelihood of purchasing insurance simply because people become more capable of assessing its benefits.

\section{DATA AND EMPIRICAL METHODOLOGY}

The majority of the explanatory variables we use in our regressions are fairly standard for empirical studies of life insurance consumption. ${ }^{6}$ For the full set of variables used, see the Appendix. The relevance of the most significant

\footnotetext{
${ }^{4}$ The above utility specification implies that bequests can be left only through insurance instruments. In reality, this is not true. Demand for insurance is affected by factors such as faith in insurance companies and savings institutions in general. In the context of the adopted theoretical framework, the lack of such faith can be expressed by assigning lower values to $b_{t}$.

${ }^{5}$ Note that such an interpretation, borrowed from Fischer (1973) is directly applicable only to term life insurance. The relationship between life expectancy and the demand for whole life insurance is less straightforward due to the presence of a substantial savings component. We discuss the effect of this heterogeneity in insurance contracts on our results later in the paper.

${ }^{6}$ The most recent textbooks on risk and insurance (see Black and Skipper, 2000, for one) list the following as factors affecting life insurance consumption: price, income, inflation, aging population, education level, household structure and extended family, industrialization and urbanization, social environment, political environment, and internationalization.
} 
variables along with the expected sign of each relationship is discussed in detail below, where we somewhat schematically split the independent variables into economic and cultural/demographic.

\section{Economic Variables}

\section{Household income}

It is widely recognized in the literature on the subject that an individual or a household starts considering life insurance only after achieving a certain level of wealth. Since the primary purpose of life insurance is to protect the household from the loss of income due to death of the primary income earner, the propensity to purchase life insurance will be greater the more substantial the potential loss. Besides, the opportunity cost of paying insurance premiums decreases with an increase in household income. Both conjectures imply it is reasonable to expect the demand for insurance to increase along with an increase in household income.

The available data sources had only aggregated information on household income. However, even the aggregate data was not completely useless. Since higher per capita income is an indication of a wealthier country, it is reasonable to expect a larger portion of the population to have an interest in purchasing life insurance. Thus we expect to see greater purchases of life insurance in countries with higher average income. We used cross-country data on the per capita GDP in nominal (GDPPC) as well as purchasing power parity (GDPPPP) terms as alternative aggregate measures of household wealth. Naturally, the latter of the two variables is expected to be the better predictor since it accounts for the cross-country differences in price levels.

Obviously, the decisions to purchase life insurance are made by individual households. Therefore, while average income level is an important characteristic of a country, it is important to include in the analysis a variable that would account for the actual distribution of wealth across households. The majority of the studies in the field do this by using the Gini coefficient.

However, prior cross-country studies of factors affecting the demand for life insurance yield conflicting results regarding the sign of the relationship between the Gini coefficient and LIPR. For instance, Beenstock et al. (1986) found this relationship to be negative. Their explanation is that insurance demand is attributed mainly to the middle class since the wealthy population does not need as much insurance protection while poor households cannot afford it, and a smaller degree of income inequality reflects a larger share of middle-income households. Contrary to their result, Beck and Webb (2003) found that countries with higher Gini coefficient and therefore less equal income distribution have higher LIPR. They explain their finding by attributing the inequality of income distribution to a larger share of wealthy households. Thus, while both views share the common notion that the demand for life insurance is attributed mainly to households with income above a certain level, their conjectures regarding the expected sign of the relationship between life insurance consumption and the Gini coefficient are different.

We attribute such a difference in prior findings to the fact that the Gini coefficient does not convey information about whether inequality in income distribution is attributed mainly to a large number of high-income or low-income households. The following diagram illustrates this point graphically. The Gini coefficient is the same for both cases of Lorenz curve pictured on the diagram, but the share of households at or above a certain income level is clearly not.

We felt that this issue deserves special attention. Thus, we used detailed cross-country data on income distribution to construct several alternative income distribution proxies, some of which, as we hoped, would perform in regressions better than the Gini coefficient. Among the alternative variables we tested were the share of income earned by the top 10 and 20 percentile of households, the share of the population receiving income above the national average, half the national average, and twice the national average, and the percentage of households above a certain income level in international purchasing power parity terms. The first two of those variables were obtained directly from the data on percentile distribution of income while the others were constructed using the procedure that is not described here for brevity. 


\section{Figure 1. The ambiguity of the Gini coefficient.}

Cumulative share of income, $\%$

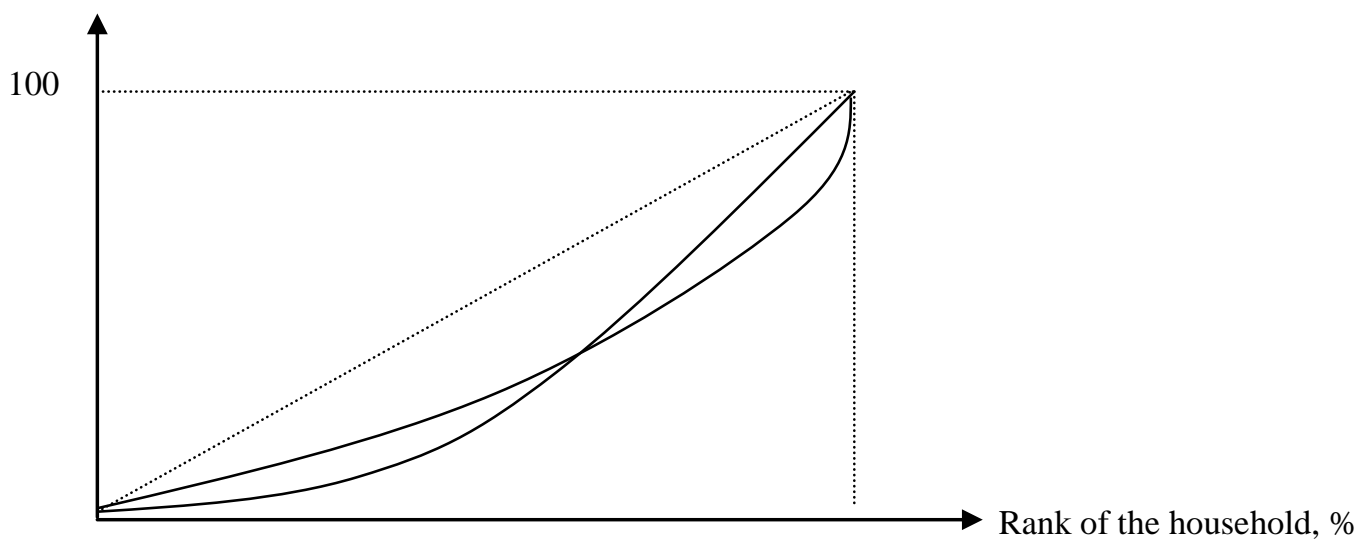

Inflation

Prior research suggests that inflation negatively affects the demand for life insurance (see Hofflander and Duvall, 1967; Babbel, 1981; Beck and Webb, 2003; and others). ${ }^{7}$ The intuition behind such a relationship is straightforward. In the context of the theoretical model, inflation decreases the marginal benefit of bequests and increases the preference for present as opposed to future consumption. As a result, we expect to see a reduction in the purchases of all assets, including life insurance policies.

On the other hand, high but steady inflation may not be as much of a factor if insurance contracts are indexed accordingly. Indeed, some of the countries in our sample have used and are using inflation-indexed life insurance products. It is therefore possible that the variation in the inflation rate may be more detrimental for the demand for life insurance than the inflation rate itself.

Since both hypotheses regarding the mechanism through which inflation affects decisions to purchase insurance make sense, we used the cross-country data on the changes on the inflation rate in years 1990-2003 and then used the average and the standard deviation of the inflation rate over a number of years ranging from 3 to 12 .

\section{Economic environment}

We felt that the actual volume of life insurance purchases could depend not only on the demand for insurance but also on the ability of insurance companies to supply it in a particular country. Supply of insurance, or insurance companies' willingness and ability to offer insurance contracts, in turn depends on the economic environment in the country of interest. A sample of factors that may matter includes the development of financial institutions, openness of the country to foreign companies, degree of property rights protection, etc. The task of formalizing and quantifying these factors is not an easy one and has to be performed consistently. To account for the type of economic environment in a particular country, we use the data from the Index of Economic Freedom (IEF) published annually by the Heritage Foundation and The Wall Street Journal. The calculation of the Index involves assigning a score to each country in ten different categories and taking the average to obtain the Index itself. In our regressions, we used the index itself, as well as the scores assigned to countries in the four categories we felt may matter the most: Capitals flows and foreign investment, Banking and finance, Property rights, and Regulation. ${ }^{8}$

\footnotetext{
${ }^{7}$ The average inflation rate seems to matter more than the variance of the inflation rate. Babbel (1981) shows using data from Brazil that during periods of inflation demand for all life insurance, indexed or not, decreases. In the empirical model estimated in Beck and Webb (2004), inflation rate volatility turns out insignificant.

${ }^{8}$ See Index of Economic Freedom (2005) for a detailed explanation of the components of the score in each category.
} 
According to the methodology of Index calculations, a lower score indicates a higher degree of economic freedom in the country. Therefore we expect to see a negative relationship between each Index score and the amount of insurance purchased.

\section{Cultural/Demographic Variables}

\section{Educational attainment}

The more educated the population, the better it understands the benefits of life insurance. In our study, we accounted for the educational attainment of the population by using the adult literacy rate, LITERACY, or the percentage of people ages 15 and above who cannot, with understanding, read and write a short, simple statement about their everyday life. We expect this variable to be positively correlated with LIPR.

\section{Life expectancy}

Prior literature on the subject acknowledges the fact that there are two ways in which life expectancy may affect the decisions to buy life insurance. Life insurance may be purchased for the purpose of transferring wealth to future generations (bequests) or simply for financing future consumption (savings). People who expect to live longer are more interested in using life insurance as a savings instrument but less interested in using it as a risk diversification mechanism. Thus the expected sign of the relationship is ambiguous. The importance of the savings component among the two would be indicated by a significant positive relationship between life expectancy and life insurance consumption, and vice versa. The two variables we used to measure the effect of the expected life span were the life expectancy at birth, LIFEEXP and the percentage of newborn infants expected to survive to age 65 if subject to current mortality rates, SURV65.

\section{Fatalism}

As discussed in Section II, it is reasonable to expect consumers in societies dominated by fatalistic philosophy to have a lower degree of risk aversion and therefore a lower demand for life insurance. While there is no perfect measure of how prevalent fatalistic ideas are in a country, it has been postulated that certain religious beliefs may be strongly correlated with fatalism. Prior studies have indicated the presence of a strong negative correlation between the share of Islamic believers in a country's population and the demand for life insurance. However, this approach didn't appear useful for the purposes of our study since Islam is not well represented in Latin America and the Western Hemisphere in general. We decided to look at the Catholic religion since we felt that among Western religions it is the most consistent with the idea of fatalism. In our analysis, we used the share of the country's population identifying themselves as Catholic as a proxy for the system of beliefs and therefore for risk preferences . The expected sign of the relationship is negative.

\section{Household composition / Number of dependents}

Since a life insurance contract helps protect the household from the severity of consequences of income loss due to the death of the primary income earner, the share of the population that actually earns income may be important. Commonly used characteristics of the household-age-composition distribution are the young dependency ratio equal to the ratio of the population of people younger than 15 years of age to the working-age (commonly set equal to 15 to 64 years of age) population, the old dependency ratio equal to the ratio of the number of people older than 64 years of age to the working-age population, and the sum of the two known as the total dependency ratio. Among those measures, we expect the young dependency ratio to matter the most due to the large role the wealth of descendants is playing in life insurance decisions, and we expect a positive relationship between that variable and LIPR. 


\section{Propensity to save}

Purchases of life insurance involve bearing immediate costs and receiving benefits later. In that sense, life insurance is part of a broader set of instruments that involve intertemporal and intergenerational transfers of wealth. Therefore, the demand for life insurance may also depend on whether such transfers are part of the country's culture and traditions, and this aspect of national culture is not related to the degree of risk aversion discussed above. According to our hypothesis, countries where savings are more common should exhibit stronger demand for life insurance.

The most common macroeconomic measures of savings are Gross Domestic Savings calculated as the difference between gross national income and public and private consumption, Gross National Savings which also include net current transfers, and Net Savings which account for capital depreciation as well. Each of those variables can be measured in absolute terms as well as a percentage of either GDP or GNI. We chose to use Gross National Savings measured as a share of GNI because they best represent the way in which the population of a country allocates its earned income.

We had some reservations regarding the appropriateness of using any of the savings variables. We couldn't rule out the possibility that it reflects the population's specific preference for assets such as bonds which are different from life insurance policies in the sense that they represent an asset that pays out in either state (dead or alive) while life insurance payout is state specific. For that reason, we list the expected sign on the relationship between gross national savings and LIPR as ambiguous. Another potential problem that could limit the variable's predictive power is the potential correlation between the share of savings in GNI and the overall wealth of the country. Fortunately, this happened not to be the case for our sample where the Pearson correlation between gross national savings and per capita national income in any given year was no more than 0.221 . To further reduce potential multicollinearity issues, the data on savings were averaged over several years (ranging from three to ten). Doing so further reduced the correlation between the savings factor and any economic variables (see Table A.2 in the Appendix) and made it safe to assume that the long-term level of savings is more of a cultural variable than an indicator of the overall wealth of the country.

\section{The Dependent Variable}

We chose to use the life insurance penetration rate (LIPR), measured as the share of a country's GDP spent on life insurance premiums, as the metric of demand for life insurance. ${ }^{9}$ The fact that LIPR measures not the units of coverage sold but the revenue from sales of life insurance is perfectly acceptable for the purpose of our study since we are interested not in the quantity demanded but in the entire demand relationship that would give us an idea of how much insurance would be purchased at any given hypothetical price. While the actual form of the demand function is unknown, the relationship between LIPR and demand is fairly straightforward. If we reasonably assume that a seller of insurance chooses the optimal price-quantity pair given the demand conditions, then an increase in demand would result in insurance companies adjusting their premiums accordingly to maximize receipts. Thus, a larger LIPR serves as an indicator of higher demand for life insurance.

A brief discussion of the role of price of each unit of insurance coverage seems appropriate here. Some prior studies of life insurance demand (Browne and Kim, 1993, and others) include the average price of a unit of insurance coverage in the set of explanatory variables. Our approach ${ }^{10}$ is different and recognizes the fact that LIPR represents the revenue from sales and therefore depends on price in a non-trivial way. The inclusion of price in the model could therefore have caused problems with the model specification, at the same time removing another degree of freedom from the model. Another reason to exclude price from statistical analysis was that, due to the nature of life insurance instruments, premiums vary broadly with the age of the policy purchaser. The cross-country differences in premiums

\footnotetext{
${ }^{9}$ An alternative variable that is used in some studies is life insurance in force, LIIF, equal to the sum of the face amounts plus dividend additions of life insurance policies outstanding and measured as a share of the country's GDP. The downside of using LIIF is that it is a stock (as opposed to a flow) variable and therefore not the best measure of demand.

${ }^{10}$ A similar approach was used in Outreville (1996).
} 
per unit of coverage may therefore reflect not the demand parameters we are interested in but such supply-side factors as life expectancy (in the model already) or the age composition of the group purchasing life insurance.

\section{The Model}

We use the ordinary least squares regression to estimate the following model:

$$
L I P R_{i}=b_{0}+b_{1 k} I N C_{k i}+b_{2} I N F L_{i}+b_{3} D E P_{i}+b_{4} L I F E_{i}+b_{5} F A T_{i}+b_{6} S A V E_{i}+b_{7} E D U C_{i}+\varepsilon_{i},
$$

where $L I P R_{i}$ is the life insurance penetration rate, defined as the percentage share of the country's GDP spent on life insurance premiums, $I N C_{k i}$ is the vector of variables accounting for income distribution in country $i, I N F L_{i}$ is the measure of the country's inflation rate, $D E P_{i}$ is the dependency ratio, defined as the ratio of the population not earning income to the working population, $L I F E_{i}$ is the variable reflecting life expectancy, $F A T_{i}$ is a variable accounting for the importance of fatalism in that country's prevailing system of beliefs, $S A V E_{i}$ is a variable reflecting the country's propensity to save, $E D U C_{i}$ is a measure of educational attainment in the country, $E N V_{i}$ is a variable accounting for the economic environment in the country, and $\varepsilon_{i}$ is the error term.

\section{The Data}

Most of the data we use in our study come from the latest issue of World Development Indicators (2005). In addition to that, we use the most recent data on life insurance penetration from Sigma (2005) and proxies of countries' economic environment from the 2005 Index of Economic Freedom (2005). The statistics on the prevalence of religious beliefs among the population were obtained from the online version of "CIA - The World Factbook" (2005). The original sample had 23 countries in it, but, due to some missing data, ${ }^{11}$ the sample was later reduced to 19 observations.

\section{ESTIMATION RESULTS}

The summary statistics for the most significant variables are provided in table 1 . The regression results for several alternative model specifications are in table 2. The specification in column 1 was the most robust and also yielded the best results in terms of the fit and the significance of the coefficients and was therefore used as the benchmark.

Most strikingly, two of the "cultural" variables we tested, the share of Catholic believers in the population and the share of gross national savings in the GDP, were significant at the 1 percent level and more significant than any other variable in all regression runs. Furthermore, the estimated coefficients for those variables and their significance turned out to be robust to the choice of model specification. The result regarding the significance of these variables is especially interesting since the savings variable was never used in empirical studies on life insurance consumption before while the proportion of Catholics in the population was used but has never shown a significant impact on life insurance consumption. This may provide some food for thought regarding the use of these variables in future empirical research on the subject.

\footnotetext{
${ }^{11}$ We were unable to obtain reliable LIPR data for Haiti and Nicaragua, and a substantial amount of data for Barbados and Bahamas. The complete data set used in the study is available upon request.
} 
Table 1. Summary statistics

\begin{tabular}{|l|l|l|l|l|}
\hline & \multicolumn{1}{|c|}{ Mean } & Standard Deviation & \multicolumn{1}{c|}{ Minimum } & Maximum \\
\hline LIPR & 0.97 & 1.33 & 0.08 & 5.77 \\
\hline CATHOLIC & 79.8 & 24.1 & 4.0 & 97.0 \\
\hline GRSAV_5 & 18.6 & 5.0 & 11.2 & 25.6 \\
\hline GNIPPP & 6330 & 2700 & 2490 & 11410 \\
\hline GINI & 50.9 & 6.7 & 37.9 & 59.9 \\
\hline TOP20 & 56.1 & 5.7 & 45.9 & 64.1 \\
\hline TOP10 & 39.8 & 5.9 & 29.9 & 48.3 \\
\hline SURV65 & 76.4 & 6.6 & 65.0 & 86.0 \\
\hline LIFEEXP & 71.6 & 4.0 & 66.0 & 79.0 \\
\hline CPI_10 & 8.23 & 16.0 & 1.1 & 68.8 \\
\hline INFLVAR3 & 4.14 & 4.96 & 0.55 & 16.0 \\
\hline Y_DEP & 0.52 & 0.12 & 0.34 & 0.79 \\
\hline OLDDEP & 0.09 & 0.03 & 0.06 & 0.20 \\
\hline TOTDEP & 0.61 & 0.10 & 0.43 & 0.85 \\
\hline LITERACY & 89.9 & 7.6 & 70.6 & 98.6 \\
\hline IEF & 3.00 & 0.54 & 1.81 & 4.09 \\
\hline
\end{tabular}

Our estimation results suggest that, would the share of the population that consider themselves Catholic decrease by 10 percent, we could expect an increase in life insurance premiums collected in the amount of roughly 0.4 percent of that country's GDP. As for the role of savings, it is reasonable to expect a one percent increase in the share of gross savings in the GDP to be accompanied by an increase in LIPR by roughly $0.12-0.15$ percent of the GDP.

We can think of two explanations for the positive relationship between gross national savings and LIPR. The most straightforward one is that collected life insurance premiums are primarily invested in the bonds market and thus add to savings. However, the low estimated value of the coefficient clearly indicates that life insurance plays only a minor role in national savings and that other factors matter as well. We suggest to interpret the share of gross national savings in GDP as an indicator of the population's attitude towards savings in general and purchasing life insurance in particular. Such a conjecture, if further confirmed, can be invaluable for assessing countries' insurance market potential.

The per capita income ${ }^{12}$ was significant as well, at least in the preferred specification. According to our results, a $\$ 1000$ increase in per capita income in purchasing power parity terms would cause the amount spent on life insurance purchases to increase by 0.15-0.2 percent of the country's GDP.

Among variables accounting for income inequality and used in combination with the per capita income, GINI performed the best (see columns 1, 5 and 6 in Table 2). The shares of national income earned by the wealthiest 10 or 20 percent of the country's population are significant only at the 10 percent level. However, the positive sign of the estimated coefficients for those variables confirms the notion that the demand for life insurance comes mostly from wealthy households. According to on of the model specifications, if the wealthiest 20 percent of a country's households were to earn an extra 10 percent of national income, there would be an increase in life insurance premiums collected in the amount of 0.5 percent of that country's GDP. The fact that the Gini coefficient produces better results may be an indication that all the countries in the sample share a similar income distribution. Still we do believe that using the data on the income of the top 10 or 20 percent of the households may be more advantageous for a broader and more diverse set of countries.

\footnotetext{
${ }^{12}$ Our expectations that accounting for purchasing power parity while calculating the per capita income should improve the quality of the overall fit turned out to be true.
} 
Table 2. Results of the OLS regression with LIPR as dependent variable. Relationships significantat the 5\% level are in bold. Standard errors are in parentheses.

\begin{tabular}{|c|c|c|c|c|c|c|c|}
\hline Specification & 1 & 2 & 3 & 4 & 5 & 6 & 7 \\
\hline Constant & $\begin{array}{c}7.813 \\
(2.911)\end{array}$ & $\begin{array}{c}4.244 \\
(3.599)\end{array}$ & $\begin{array}{c}7.607 \\
(3.036)^{*}\end{array}$ & $\begin{array}{c}7.896 \\
(2.885)^{*}\end{array}$ & $\begin{array}{c}8.655 \\
(3.196)^{*}\end{array}$ & $\begin{array}{c}9.637 \\
(3.048) * *\end{array}$ & $\begin{array}{l}1.933 \\
(2.665)\end{array}$ \\
\hline $\begin{array}{l}\text { CATHOLIC } \\
(-)\end{array}$ & $\begin{array}{c}-0.0439 \\
(0.007)^{* *}\end{array}$ & $\begin{array}{c}-0.0464 \\
(0.006)^{* *}\end{array}$ & $\begin{array}{c}-0.0447 \\
(0.007)^{* *}\end{array}$ & $\begin{array}{c}-0.0403 \\
(0.007)^{* *}\end{array}$ & $\begin{array}{c}-0.0414 \\
(0.007)^{* *}\end{array}$ & $\begin{array}{c}-0.0402 \\
(0.007) * *\end{array}$ & $\begin{array}{c}-0.0432 \\
(0.007)^{* *}\end{array}$ \\
\hline $\begin{array}{l}\text { GRSAV_5 } \\
(?)\end{array}$ & $\begin{array}{c}0.134 \\
(0.023)^{* *}\end{array}$ & $\begin{array}{c}0.149 \\
(0.024)^{* *}\end{array}$ & $\begin{array}{c}0.136 \\
(0.024)^{* *}\end{array}$ & $\begin{array}{c}0.135 \\
(0.023)^{* *}\end{array}$ & $\begin{array}{c}0.123 \\
(0.025)^{* *}\end{array}$ & $\begin{array}{c}0.123 \\
(0.025)^{* *}\end{array}$ & $\begin{array}{c}0.142 \\
(0.024)^{* *}\end{array}$ \\
\hline $\begin{array}{l}\text { LIFEEXP } \\
(?)\end{array}$ & $\begin{array}{c}-0.233 \\
(0.044)^{* *}\end{array}$ & $\begin{array}{c}-0.232 \\
(0.041)^{* *}\end{array}$ & $\begin{array}{c}-0.237 \\
(0.046)^{* *}\end{array}$ & $\begin{array}{c}-0.231 \\
(0.043)^{* *}\end{array}$ & $\begin{array}{c}-0.231 \\
(0.049)^{* *}\end{array}$ & $\begin{array}{c}-0.227 \\
(0.049)^{* *}\end{array}$ & \\
\hline $\begin{array}{l}\text { LITERACY } \\
(+)\end{array}$ & $\begin{array}{c}0.0977 \\
(0.027)^{* *}\end{array}$ & $\begin{array}{c}0.118 \\
(0.028)^{* *}\end{array}$ & $\begin{array}{c}0.100 \\
(0.028)^{* *}\end{array}$ & $\begin{array}{c}0.0950 \\
(0.027)^{* *}\end{array}$ & $\begin{array}{c}0.0858 \\
(0.029)^{*}\end{array}$ & $\begin{array}{c}0.0834 \\
(0.028)^{*}\end{array}$ & $\begin{array}{c}0.107 \\
(0.030)^{* *}\end{array}$ \\
\hline $\begin{array}{l}\text { IEF } \\
(-)\end{array}$ & $\begin{array}{c}-0.751 \\
(0.224)^{* *}\end{array}$ & $\begin{array}{c}-0.792 \\
(0.213)^{* *}\end{array}$ & $\begin{array}{c}-0.706 \\
(0.246)^{*}\end{array}$ & $\begin{array}{l}-0.543 \\
(0.292)\end{array}$ & $\begin{array}{c}-0.765 \\
(0.248)^{*}\end{array}$ & $\begin{array}{c}-0.750 \\
(0.251)^{*}\end{array}$ & $\begin{array}{c}-0.457 \\
(0.024)^{* *}\end{array}$ \\
\hline $\begin{array}{l}\text { GINI } \\
(?)\end{array}$ & $\begin{array}{c}0.0659 \\
(0.025)^{*}\end{array}$ & $\begin{array}{c}0.0612 \\
(0.023)^{*}\end{array}$ & $\begin{array}{c}0.0699 \\
(0.027)^{*}\end{array}$ & $\begin{array}{l}0.0482 \\
(0.029)\end{array}$ & & & $\begin{array}{c}0.063 \\
(0.026)^{*}\end{array}$ \\
\hline $\begin{array}{l}\text { GNIPPP } \cdot 10^{-3} \\
(+)\end{array}$ & $\begin{array}{c}0.157 \\
(0.060)^{*}\end{array}$ & $\begin{array}{c}0.213 \\
(0.067)^{*}\end{array}$ & $\begin{array}{c}0.157 \\
(0.062)^{*}\end{array}$ & $\begin{array}{c}0.181 \\
(0.063)^{*}\end{array}$ & $\begin{array}{c}0.189 \\
(0.063)^{*}\end{array}$ & $\begin{array}{c}0.192 \\
(0.063)^{*}\end{array}$ & $\begin{array}{c}0.144 \\
(0.063)^{*}\end{array}$ \\
\hline $\begin{array}{l}\text { Y_DEP } \\
(+)\end{array}$ & & $\begin{array}{c}3.044 \\
(1.984) \\
\end{array}$ & & & & & \\
\hline $\begin{array}{l}\text { CPI_10 } \\
(-)\end{array}$ & & & $\begin{array}{l}-0.004 \\
(0.008)\end{array}$ & & & & \\
\hline $\begin{array}{l}\text { INFLVAR3 } \\
(-)\end{array}$ & & & & $\begin{array}{l}-0.0384 \\
(0.035)\end{array}$ & & & \\
\hline $\begin{array}{l}\text { TOP20 } \\
(+)\end{array}$ & & & & & $\begin{array}{l}0.0582 \\
(0.030)\end{array}$ & & \\
\hline $\begin{array}{l}\text { TOP10 } \\
(+)\end{array}$ & & & & & & $\begin{array}{l}0.0519 \\
(0.028)\end{array}$ & \\
\hline $\begin{array}{l}\text { SURV65 } \\
\text { (?) }\end{array}$ & & & & & & & $\begin{array}{c}-0.148 \\
(0.030)^{* *}\end{array}$ \\
\hline Observations & 19 & 19 & 19 & 19 & 19 & 19 & 19 \\
\hline $\mathrm{R}^{2}$ & 0.929 & 0.943 & 0.931 & 0.937 & 0.913 & 0.911 & 0.921 \\
\hline Adjusted $\mathrm{R}^{2}$ & 0.884 & 0.897 & 0.876 & 0.886 & 0.858 & 0.854 & 0.870 \\
\hline
\end{tabular}

** - variable significant at the $1 \%$ level;

- variable significant at the $5 \%$ level.

Contrary to our expectations, the results regarding the variables we constructed for use as alternative proxies of income distribution were somewhat disappointing. Replacing the combination of GDPPPP and TOP20 with the best among the constructed variables accounting for income inequality, PPP8000, reduced the quality of the fit substantially while including PPP8000 and keeping one of the two aforementioned variables in the model resulted in severe multicollinearity problems. Those results are not presented here for brevity.

As we expected, education turned out to positively affect the demand for life insurance. According to the estimation results, a 1 percent increase in a country's literacy rate would result in an increase in receipts from life insurance premiums in the amount of 0.1 percent of the country's GDP. 
Both variables accounting for life expectancy, SURV65 and LIFEXP, performed well, with the latter performing marginally better. In both cases the relationship between the expected life span and the purchases of life insurance was negative and significant at the 1 percent level. Overall, our model predicts that a one-year increase in life expectancy would result in a reduction in the volume of life insurance premiums paid in the amount of 0.23 percent of the country's GDP. The negative sign of the relationship is a clear indication that in the countries included in the sample the bequest motive for life insurance purchases dominates the saving-for-retirement motive. ${ }^{13}$ This is consistent with a number of empirical findings. ${ }^{14}$

All the proxies we used to account for the economic environment in a country were negatively correlated with LIPR and significant at the 10 percent level, with the overall index performing the best.

Our results regarding the effects of inflation are mixed. The most straightforward measure of inflation, CPI over a certain period, performed poorly, exhibiting sign ambiguity and extremely low significance. This may be due to the earlier expressed idea that the inflation rate itself is not so much a factor since it can be compensated for by buying insurance contracts adjusted for inflation. The variance in the inflation rate had a negative impact on the demand for life insurance, but the significance of that relationship was lower than expected (30 percent at best, see column 4 in Table 2). According to our results, were the standard deviation of the annual inflation rate over three years to increase by 10 percent on the annual basis, the purchases of life insurance would decrease by 0.4 percent of the GDP. Since such a high variation in the inflation rate is clearly a sign of severe macroeconomic instability, we have reservations regarding the overall economic significance of inflation indicators.

Among the variables reflecting the age composition of the population, the young dependency ratio performed the best. This is not surprising given the facts that children are often primary beneficiaries of life insurance contracts and that a larger number of children increases the risk aversion of the primary income earner. However, even Y_DEP was significant only at the 20 percent level. Such a low significance is somewhat surprising since the coefficient on life expectancy implies that bequests are the primary reason to purchase life insurance. One possible explanation for this fact is the difference in demographics across households with different income. Using a single statistic for the dependency ratio will cause counterintuitive results if, for example, high-income households tend to have a smaller number of children than low-income ones. To find out whether this is indeed the case, we need access to detailed data on household demographics, which did not appear feasible at the time of this study. Another explanation is the role played by extended families in many Latin American countries. An effectively larger size of a family leads to risk diversification and therefore a weaker effect of the number of immediate descendants on the demand for risk-reducing life insurance instruments. ${ }^{15}$

\section{CONCLUDING REMARKS}

Our study focuses on a geographic region no one has looked at in isolation. There are several contributions this paper makes to the literature on the subject. All of them add to the understanding of cross-country differences in decisions to buy life insurance and may be relevant for a broader set of countries.

One result is that the prevalence of certain religious beliefs can strongly influence life insurance consumption, perhaps through their association with fatalism. The choice of the region for our study determined the choice of the Catholic religion as a proxy for fatalism since Islam, which prior studies looked at is not well represented in the Western Hemisphere. This result may be useful for companies targeting other regions as well since,

\footnotetext{
${ }^{13}$ See Babbel and Ohtsuka (1989), who used a theoretical model to show that whole life insurance, term insurance, and savings are components of an optimal consumption-investments plan rather than substitutes for each other.

${ }^{14}$ Bernheim (1991) showed that term life insurance is purchased for reasons different from those for any other types of insurance and that term life insurance holdings are positive only in the presence of strong bequest motives. Chuma (1994) and Walliser and Winter (1998) used data sets from Japan and Germany, respectively and found a significantly positive effect of intended bequest motives on the demand for life insurance.

${ }^{15}$ This aligns well with responses received during a series of informal interviews one of the authors has conducted in Latin America. A common response there was that insurance protection is unnecessary since the respondents felt that if something happened to them other members of the extended family would take care of the survivors.
} 
once the predominantly Islamic countries are excluded from the set of countries as not very promising markets for life insurance, insurance companies may be interested in how to rank the remaining countries in terms of their potential.

The other variable that worked extremely well as a predictor for life insurance consumption was the share of gross savings in the gross national income. In our data set, this variable was weakly correlated with the average income level, which confirmed our hypothesis that a greater proportion represented by savings in the country's national income should not be attributed only to economic factors. We believe it can be perceived as a characteristic of the country's culture and traditions and may serve as an indicator of a potentially more favorable attitude of that country's population toward life insurance.

As Table 2 indicates, results regarding both cultural determinants of demand for life insurance, which we view as the most important findings of our paper, are robust to the choice of the empirical model specification as well as proxies we use to measure certain countries' characteristics. We find this fact encouraging, especially considering the small size of the sample and the fact that the data on the sales of life insurance bundle together different types of policies, some of which may be purchased to cover different risks. ${ }^{16}$

Another finding of our study that may be of interest to researchers in the field is the significant negative effect life expectancy has on the consumption of life insurance. This fact allows us to conclude that in the region of interest, the demand for life insurance products is primarily driven by bequest motives.

Our findings may be valuable to researchers and practitioners in the field of international finance as well as insurance companies doing business around the world. Most importantly, they suggest that cultural factors that often get overlooked in studies of life insurance markets need to be investigated more thoroughly. Finding a proper proxy for the cultural component in those regions would help insurance companies better understand the cultural specifics and the potential of a particular country's market for life insurance, and our study is a step in that direction.

Of course, no empirical study can explain everything. In a study of life insurance, it is especially true since there are numerous factors that are hard to quantify. One example of such a factor in our case is people's attitude toward insurance companies. One of the responses in the aforementioned interviews in Latin America was that the people did not trust insurance companies because of bad experiences in the past. The role of extended families or another form of an informal safety net is another factor that is relevant but very hard to control for.

In our future research, we plan to explore the importance and relevance of cultural proxies using a larger sample of countries. Other directions for further research include a more in-depth look at the effect of dependency ratio on life insurance purchases and possibly disentangling supply-side and demand-side effects on the overall amount of life insurance purchased.

\section{REFERENCES}

1. Babbel, D.F. (1981), Inflation, Indexation and Life Insurance Sales in Brazil, The Journal of Risk and Insurance, 48 , pp.115-135.

2. Babbel, D.F. and E.Ohtsuka (1989), Aspects of Optimal Multiperiod Life Insurance, The Journal of Risk and Insurance, 56, pp.460-481.

3. Beck, T. and I. Webb (2003), Economic, Demographic, and Institutional Determinants of Life Insurance Consumption across Countries, World Bank Economic Review, 17, pp. 51-88.

4. Beenstock, M., G.Dickinson, and S. Khajuria (1986), The Determination of Life Premiums: An International Cross-Sectional Analysis, Insurance: Mathematics and Economics, 5, pp.261-270.

5. Bernheim, B. D. (1991), How Strong Are Bequest Motives? Evidence Based on Estimates of the Demand for Life Insurance and Annuities, Journal of Political Economy, 99, pp. 899-927.

6. $\quad$ Black, K. and H.D. Skipper (2000), Life and Health Insurance, $13^{\text {th }}$ ed., Prentice Hall.

\footnotetext{
${ }^{16}$ Browne and Kim (1993) and Beck and Webb (2004) use this fact to explain the low significance of relationships in studies similar to ours.
} 
7. Browne, M.J. and K. Kim (1993), An International Analysis of Life Insurance Demand, The Journal of Risk and Insurance, 60, pp.616-634.

8. Burnett, J.J. and B.A. Palmer (1984), Examining Life Insurance Ownership through Demographic and Psychographic Characteristics, The Journal of Risk and Insurance, 51, pp.453-467.

9. Campbell, R. A. (1980), The Demand for Life Insurance: An Application of the Economics of Uncertainty, The Journal of Finance, 35, pp.1155-1172.

10. Carreyrou, J., M. Murray, J. Hookway, and J. deCordoba (2003), Pope John Paul II's Legacy: Growing Flock, Widening Rifts, The Wall Street Journal, Oct 17, 2003.

11. Chuma, H. (1994), Intended Bequest Motives, Savings and Life Insurance Demand, in Savings and Bequests, ed. by T. Tachibanaki, Ann Arbor: University of Michigan Press.

12. CIA - The World Factbook (2005), data last updated June 14, 2005, accessed online at http://www.cia.gov/cia/publications/factbook/ on July 5,2005.

13. Douglas, M. and A. Wildavsky (1982), Risk and Culture, Berkeley: University of California Press.

14. Fischer, S. (1973), A Life Cycle Model of Life Insurance Purchases, International Economic Review, 14, pp.132-152.

15. Faulkner, J. (2002), Culture and Corruption: The Development of Insurance in Post-Communist Countries, presented at UK Insurance Economists Conference April 2002, Nottingham University Business School, UK.

16. Hill, C.W.L. (2005), International Business: Competing in the Global Marketplace, $5^{\text {th }}$ ed., McGraw Hill Irwin.

17. Hofflander, A.E. and R.M. Duvall (1967), Inflation and Sales of Life Insurance, The Journal of Risk and Insurance, 34, pp. 355-361.

18. Lewis, F.D. (1989), "Dependents and the Demand for Life Insurance," The American Economic Review, 79, pp.452-467.

19. Miles, M.A., E.J. Feulner, Jr., and M.A. O'Grady, eds., Index of Economic Freedom (2005), Heritage Foundation.

20. Outreville, J.F. (1996), Life Insurance Markets in Developing Countries, The Journal of Risk and Insurance, 63, pp. 263-278.

21. Pissarides, C.A. (1980), The Wealth-Age Relation with Life Insurance, Economica, 47, pp.451-457.

22. Sigma (2005), World Insurance in 2004: growing premiums and stronger balance sheets, Sigma No. 2/2005, Swiss Re.

23. Truett, D.B. and L.J. Truett (1990), The demand for life insurance in Mexico and the United States: A Comparative Study, The Journal of Risk and Insurance, 57, pp.321-328.

24. Walliser, J. and J. K. Winter (1998), Tax Incentives, Bequest Motives and the Demand for Life Insurance: Evidence from Germany, Discussion Paper No.99-28, Sonderforschungsbereich 504, University of Mannheim.

25. World Development Indicators (2005), The World Bank.

26. Yaari, M. (1965), Uncertain Lifetime, Life Insurance, and the Theory of the Consumer, The Review of Economic Studies, 32, pp. 137-150. 


\section{APPENDIX - A.1. VARIABLES USED IN MODEL ESTIMATIONS}

\section{Table A.1. The full set of variables used for estimation.}

\begin{tabular}{|c|c|c|}
\hline Variable & Definition & $\begin{array}{l}\text { Expected } \\
\text { sign }\end{array}$ \\
\hline GDPPC & Nominal GDP per capita & + \\
\hline GNIPPP & GNI per capita in purchasing power parity (PPP) terms & + \\
\hline LITER & Literacy rate among people ages 15 and above & + \\
\hline LIFEXP & Life expectancy at birth & $?$ \\
\hline SURV65 & $\begin{array}{l}\text { Percentage of newborn infants expected to survive to age } 65 \text {, if subject to current } \\
\text { mortality rates }\end{array}$ & $?$ \\
\hline CATHOLIC & Percentage of population identifying themselves as Catholics & - \\
\hline GRSAV_X & Gross national savings as percentage of GNI, averaged over X years & $?$ \\
\hline GINI & Gini coefficient & ? \\
\hline TOP10 & Share of national income earned by top 10 percent of households & + \\
\hline TOP20 & Share of national income earned by top 20 percent of households & + \\
\hline AVERINC & Share of households that earn less than the country's average income & - \\
\hline HALFAVER & Share of households that earn less than half the country's average income & - \\
\hline DBLAVER & Share of households that earn less than twice the country's average income & - \\
\hline PPP5000 & Share of households earning less than $\$ 5000$ in purchasing power parity terms & - \\
\hline PPP8000 & Share of households earning less than $\$ 8000$ in purchasing power parity terms & - \\
\hline Y_DEP & $\begin{array}{l}\text { Young dependency ratio; the ratio of people younger than } 15 \text { years of age to the working- } \\
\text { age population, } 15<\text { age }<64\end{array}$ & + \\
\hline CPI_X & $\begin{array}{l}\text { Change in the consumer price index over } \mathrm{X} \text { years prior to the year from which the data } \\
\text { was drawn }\end{array}$ & - \\
\hline INFLVARX & Standard deviation in the annual inflation rate over $\mathrm{X}$ years & - \\
\hline OLDDEP & $\begin{array}{l}\text { Old dependency ratio; the ratio of people older than } 64 \text { years of age to the working-age } \\
\text { population, } 15<\text { age }<64\end{array}$ & $?$ \\
\hline TOTDEP & $\begin{array}{l}\text { Total dependency ratio, equal to the sum of the young dependency ratio and the old } \\
\text { dependency ratio }\end{array}$ & + \\
\hline IEF & The country's Index of Economic Freedom score & - \\
\hline BANKFIN & $\begin{array}{l}\text { The country's score in the 'Banking and finance' category in the Index of Economic } \\
\text { Freedom }\end{array}$ & - \\
\hline FORINV & $\begin{array}{l}\text { The country's score in the 'Capital flows and foreign investment' category in the Index of } \\
\text { Economic Freedom }\end{array}$ & - \\
\hline PROPERTY & The country's score in the 'Property rights' category in the Index of Economic Freedom & - \\
\hline REGUL & The country's score in the 'Regulation' category in the Index of Economic Freedom & - \\
\hline
\end{tabular}


Table A.2. Correlation matrix.

\begin{tabular}{|c|c|c|c|c|c|c|c|c|c|c|c|c|c|c|}
\hline & LIPR & CATHOLIC & GRSAV_5 & LIFEEXP & LITERACY & IEF & GINI & GNIPPP & SURV65 & TOP20 & TOP10 & Y_DEP & OLDDEP & INFLVAR3 \\
\hline LIPR & 1 & & & & & & & & & & & & & \\
\hline CATHOLIC & -0.615 & 1 & & & & & & & & & & & & \\
\hline GRSAV_5 & 0.425 & -0.081 & 1 & & & & & & & & & & & \\
\hline LIFEEXP & 0.204 & -0.326 & 0.109 & 1 & & & & & & & & & & \\
\hline LITERACY & 0.311 & -0.109 & 0.058 & 0.706 & 1 & & & & & & & & & \\
\hline IEF & -0.457 & 0.326 & 0.153 & -0.253 & -0.148 & 1 & & & & & & & & \\
\hline GINI & -0.272 & 0.567 & -0.184 & -0.193 & -0.330 & 0.089 & 1 & & & & & & & \\
\hline GNIPPP & 0.478 & -0.120 & 0.046 & 0.587 & 0.625 & -0.301 & 0.046 & 1 & & & & & & \\
\hline SURV65 & 0.250 & -0.332 & 0.146 & 0.987 & 0.741 & -0.284 & -0.235 & 0.587 & 1 & & & & & \\
\hline TOP20 & -0.304 & 0.574 & -0.067 & -0.176 & -0.324 & 0.152 & 0.932 & -0.028 & -0.218 & 1 & & & & \\
\hline TOP10 & -0.268 & 0.532 & -0.063 & -0.174 & -0.326 & 0.120 & 0.920 & -0.024 & -0.214 & 0.994 & 1 & & & \\
\hline Y_DEP & -0.534 & 0.358 & -0.281 & -0.672 & -0.765 & 0.286 & 0.350 & -0.741 & -0.703 & 0.337 & 0.324 & 1 & & \\
\hline OLDDEP & 0.136 & -0.274 & -0.188 & 0.502 & 0.509 & -0.302 & -0.304 & 0.530 & 0.506 & -0.325 & -0.343 & -0.587 & 1 & \\
\hline INFLVAR3 & -0.288 & 0.254 & 0.200 & -0.007 & 0.208 & 0.588 & -0.267 & 0.045 & 0.009 & -0.069 & -0.097 & -0.190 & 0.273 & 1 \\
\hline CPI_10 & -0.038 & 0.082 & 0.127 & -0.095 & -0.044 & 0.338 & 0.203 & -0.009 & -0.151 & 0.258 & 0.238 & -0.218 & -0.114 & 0.212 \\
\hline
\end{tabular}



NOTES 